\title{
Risk Factors for Delayed Diagnosis of Scabies in Hospitalized Patients From Long-Term Care Facilities
}

\author{
Chorng-Jang Lay ${ }^{\mathrm{a}, \mathrm{b}, \mathrm{c}}$, Chun-Lung Wang, ${ }^{\mathrm{a}, \mathrm{b}}$, , Hui-Ying Chuang ${ }^{\mathrm{b}}$, Ya-Lan Chen ${ }^{\mathrm{b}}$, \\ Hsiang-Ling Chen ${ }^{b}$, Shu-Juan Tsai ${ }^{b}$, Chen-Chi Tsaia ${ }^{a, b, c, d}$
}

\begin{abstract}
Background: Delayed diagnosis of scabies can cause an institutional outbreak, which causes considerably economic burden to control. This study was to find the risk factors for delayed diagnosis of scabies in hospitalized patients from long-term care facilities.
\end{abstract}

Methods: We conducted a retrospective analysis of the hospitalized patients from long-term care facilities, diagnosed to have scabies between January 2006 and December 2008. A stepwise logistic regression analysis was performed to determine the risk factors for delayed diagnosis of scabies.

Results: A total of 706 episodes with scabies were identified retrospectively in 399 hospitalized patients from long-term care facilities. Of these, 44 episodes were considered as delayed diagnosis of scabies. These patients were more associated with chronic usage of steroid $(73 \%$ vs. $10 \%, \mathrm{P}<0.001)$ and had longer duration of hospitalization than the others ( 30 vs. 13 days, $\mathrm{P}<0.001)$. After logistic regression, steroid therapy was the risk factor of delayed diagnosis of scabies (odds ratio: 23.493).

Conclusions: In the patients from long-term care facilities, clinical physicians should pay more attention to those with chronic usage of steroid to avoid delayed diagnosis of scabies.

Keywords: Scabies; Delayed diagnosis; Risk factor; Long-term care facility

\footnotetext{
Manuscript accepted for publication March 2, 2011

${ }^{a}$ Division of Infectious Disease, Department of Medicine, Buddhist Dalin Tzu Chi General Hospital, Chiayi, Taiwan

${ }^{\mathrm{b}}$ Infection Control Committee, Buddhist Dalin Tzu Chi General

Hospital, Chiayi, Taiwan

${ }^{\mathrm{c} S} \mathrm{School}$ of Medicine, Tzu Chi University, Hualien, Taiwan

${ }^{\mathrm{d}}$ Corresponding author: Chen-Chi Tsai, Division of Infectious Disease, Department of Medicine, Buddhist Dalin Tzu Chi General Hospital, 2, Min-Sheng Road, Dalin, Chiayi, Taiwan.

Email: antibody1@msn.com
}

doi:10.4021/jocmr520w

\section{Introduction}

Scabies, caused by Sarcoptes scabiei var hominis is a polymorphic disease that can cause protean cutaneous manifestations [1]. It distributes worldwide and affects 300 million individuals annually, encompassing all age groups and social classes [2]. With aging of population in recent decades, demand of long-term care facilities increased in industrialized countries. Crowded environment and centralized management in long-term care facilities accelerate the spreading of scabies and cause outbreaks [3]. When the patients with scabies are admitted to acute care facilities, delayed diagnosis causes institutional scabies outbreaks. Control of these outbreaks is associated with a considerable working and economic burden including ward closures, patient's treatment and environmental disinfection procedures, laundry and extra staffing [4-6]. In addition, institutional scabies outbreaks may lead to adverse public perception of the establishment and panic among the residents' family member, what is more, they cause a media frenzy and elicit fear of infection in medical personnel [7].

Scabies were found in $3.3 \%$ of the total population in long-term care facilities in Taiwan [8]. This patient group is the major population diagnosed to have scabies in hospitals. An epidemiological survey also showed that hospitals that possessed acute care and long-term care wards indicated higher prevalence of scabies [4]. Even though delayed diagnosis of scabies is the most important factor for outbreaks, however, there are no clinical studies to find the risk factors for delayed diagnosis of scabies in this patient group. Therefore, we conducted a retrospective study to find the risk factors for delayed diagnosis of scabies in hospitalized patients from long-term care facilities.

\section{Methods}

\section{Study population}

The hospitalized patients from long-term care facilities, diagnosed with scabies at Buddhist Tzu Chi Dalin General 
Table 1. Clinical Characteristics of Hospitalized Patients With Scabies From Long-Term Care Facilities

\begin{tabular}{|c|c|}
\hline Age (years), mean \pm SD & $80 \pm 8.8$ \\
\hline Gender (male : female) & $347: 359$ \\
\hline Duration from admission to diagnosis of scabies (days), mean (range) & $1(0-12)$ \\
\hline Duration of hospitalization (days), mean (range) & $14(1-388)$ \\
\hline \multicolumn{2}{|l|}{ Underlying disease } \\
\hline Chronic respiratory failure, $\mathrm{n}(\%)$ & $288(41)$ \\
\hline Congestive heart failure, $\mathrm{n}(\%)$ & $96(14)$ \\
\hline End stage renal disease, $\mathrm{n}(\%)$ & $35(5)$ \\
\hline Scabies infection before, $\mathrm{n}(\%)$ & $360(51)$ \\
\hline Cirrhosis, n (\%) & $20(3)$ \\
\hline Pressure sore, $\mathrm{n}(\%)$ & $93(13)$ \\
\hline Malignancy, n (\%) & $45(6)$ \\
\hline Diabetes mellitus, $\mathrm{n}(\%)$ & $293(42)$ \\
\hline Hypertension, n (\%) & $567(80)$ \\
\hline Bedridden status, $\mathrm{n}(\%)$ & $610(86)$ \\
\hline Steroid therapy, n (\%) & $97(14)$ \\
\hline Anti-parkinsonism agent therapy, $\mathrm{n}(\%)$ & $103(15)$ \\
\hline Anti-seizure therapy, n (\%) & $186(26)$ \\
\hline Bacteremia during hospitalization, $\mathrm{n}(\%)$ & $225(32)$ \\
\hline \multicolumn{2}{|l|}{ Laboratory data } \\
\hline White leukocyte $\left(10^{3} / \mu \mathrm{L}\right)$, mean $\pm \mathrm{SD}$ & $13.3 \pm 7.4$ \\
\hline Eosinophil count $(/ \mu \mathrm{L})$, mean $\pm \mathrm{SD}$ & $410(0-43025)$ \\
\hline Hemoglobulin $(\mathrm{g} / \mathrm{dL})$, mean $\pm \mathrm{SD}$ & $10.6 \pm 2.0$ \\
\hline Serum sodium $(\mathrm{mmol} / \mathrm{L})$, mean $\pm \mathrm{SD}$ & $130.4 \pm 9.1$ \\
\hline Serum potassium $(\mathrm{mmol} / \mathrm{L})$, mean $\pm \mathrm{SD}$ & $4.1 \pm 0.9$ \\
\hline Serum creatinine $(\mathrm{mg} / \mathrm{dL})$, mean $\pm \mathrm{SD}$ & $1.3 \pm 1.2$ \\
\hline Serum urea nitrogen $(\mathrm{mg} / \mathrm{dL})$, mean $\pm \mathrm{SD}$ & $26.4 \pm 22.5$ \\
\hline Serum albumin $(\mathrm{g} / \mathrm{dL})$, mean $\pm \mathrm{SD}$ & $2.8 \pm 0.7$ \\
\hline Serum glutamic oxaloacetic transaminase (IU/L), mean (range) & $35.6(6-1375)$ \\
\hline
\end{tabular}

$\mathrm{SD}=$ standard deviation

Hospital between January 2006 and December 2008 were enrolled in this study. This hospital was an 890-bed regional hospital with special ward for the patients from long-term care facilities. Their medical records were reviewed and the data including demographic characteristics, medical history, underlying diseases, medications, and laboratory data were collected for analysis.

\section{Definition of terms}

A patient was considered to have scabies if any of the following was noted during his hospital stay: 1) clinical diagnosis according to the opinion of the dermatologist, 2) finding of scabies or its eggs in skin furfur under the microscope, 3) clinical diagnosis according their physicians and improvement of skin lesions under the therapy for scabies. The diagnosis was considered to be delayed if a patient was diagnosed with scabies 48 hours after admission. Corticosteroid treatment was defined as usage of a dose equivalent to at least $10 \mathrm{mg}$ prednisolone per day for more than 14 days within 4 weeks before diagnosis of scabies [9]. Renal function impairment was defined as less than $50 \mathrm{ml} / \mathrm{min}$ of estimated creatinine clearance, calculated according to the laboratory data at admission. The diagnosis of cirrhosis was made on 
Table 2. Univariate Analysis of Risk Factors for Delayed Diagnosis of Scabies in Hospitalized Patients From LongTerm Care Facilities

\begin{tabular}{|c|c|c|c|}
\hline Variable & $\begin{array}{l}\text { Delayed diagnosis } \\
(\mathrm{n}=44)\end{array}$ & $\begin{array}{l}\text { Early diagnosis } \\
(\mathrm{n}=662)\end{array}$ & Pvalue \\
\hline Age (years), mean $\pm \mathrm{SD}$ & $78 \pm 7.5$ & $80 \pm 8.9$ & 0.223 \\
\hline Duration of hospitalization, days (range) & $30(6-388)$ & $13(1-221)$ & $<0.001^{*}$ \\
\hline Male, n (\%) & $27(61)$ & $320(48)$ & 0.129 \\
\hline \multicolumn{4}{|l|}{ Underlying disease } \\
\hline Chronic respiratory failure, $\mathrm{n}(\%)$ & $18(41)$ & $270(41)$ & 1.000 \\
\hline Congestive heart failure, $\mathrm{n}(\%)$ & $4(9)$ & $92(14)$ & 0.501 \\
\hline End stage renal disease, $\mathrm{n}(\%)$ & $4(9)$ & $31(5)$ & 0.266 \\
\hline Scabies infection before, $\mathrm{n}(\%)$ & $19(43)$ & $341(52)$ & 0.360 \\
\hline Cirrhosis, n (\%) & $0(0)$ & $20(3)$ & 0.629 \\
\hline Pressure sore, $\mathrm{n}(\%)$ & $8(18)$ & $85(13)$ & 0.433 \\
\hline Malignancy, n (\%) & $5(11)$ & $40(6)$ & 0.190 \\
\hline Diabetes mellitus, n (\%) & $20(45)$ & $273(41)$ & 0.695 \\
\hline Hypertension, n (\%) & $32(73)$ & $535(81)$ & 0.267 \\
\hline Bedridden status, $\mathrm{n}(\%)$ & $41(93)$ & $569(86)$ & 0.259 \\
\hline Steroid therapy, n (\%) & $32(73)$ & $65(10)$ & $<0.001 *$ \\
\hline Anti-parkinsonism therapy, n (\%) & $4(9)$ & $99(15)$ & 0.397 \\
\hline Anti-seizure therapy, n (\%) & $13(30)$ & $173(26)$ & 0.748 \\
\hline Bacteremia, n (\%) & $15(34)$ & $210(32)$ & 0.873 \\
\hline \multicolumn{4}{|l|}{ Laboratory data } \\
\hline Leukocytosis, n (\%) & $24(55)$ & $378(59)$ & 0.862 \\
\hline Eosinophilia, n (\%) & $12(27)$ & $116(18)$ & 0.104 \\
\hline Anemia, n (\%) & $22(50)$ & $243(37)$ & 0.109 \\
\hline Hyponatremia, n (\%) & $28(64)$ & $450(68)$ & 0.647 \\
\hline Hypokalemia, n (\%) & $11(25)$ & $156(24)$ & 0.982 \\
\hline Renal function impairment, $\mathrm{n}(\%)$ & $10(23)$ & $145(22)$ & 1.000 \\
\hline Hypoalbuminemia, n (\%) & $32(73)$ & $454(69)$ & 0.684 \\
\hline Liver function impairment, $\mathrm{n}(\%)$ & $12(27)$ & $181(27)$ & 1.000 \\
\hline
\end{tabular}

$\mathrm{SD}=$ standard deviation

*: $\mathrm{P}<0.05$

the basis of usual clinical, biological and endoscopic signs of liver disease. Chronic hypoxia $\left(\mathrm{PaO}_{2}<60 \mathrm{mmHg}\right)$, or carbon dioxide retention $\left(\mathrm{PaCO}_{2}>55 \mathrm{mmHg}\right)$ was considered as chronic respiratory failure. A patient was diagnosed with congestive heart failure by their physical condition such as pulmonary congestion, or peripheral edema, electrocardi- ography, chest film, and echocardiography by their clinical physicians. Leukocytosis was defined as more than $12 \times 10^{3 /}$ $\mu \mathrm{L}$ in blood, and eosinophilia as more than $500 / \mu \mathrm{L}$ eosinophils in blood. Anemia was defined as less than $10 \mathrm{~g} / \mathrm{dL}$ hemoglobulin in blood. Serum sodium $\leq 130 \mathrm{mmol} / \mathrm{L}$ was considered as hyponatremia, serum potassium $\leq 3.5 \mathrm{mmol} / \mathrm{L}$ 
Table 3. Multivariate Logistic Regression Analysis of Risk Factors Associated With Delayed Diagnosis of Scabies in the Hospitalized Patients From Long-Term Care Facilities

\begin{tabular}{llll}
\hline Variable & Odds ratio & 95\% confidence interval & P value \\
\hline Steroid therapy & 23.493 & $11.354-48.612$ & $<0.001$ \\
\hline
\end{tabular}

as hypokalemia, and serum albumin $\leq 3 \mathrm{~g} / \mathrm{dL}$ as hypoalbuminemia. Chronically impairment of serum glutamic oxaloacetic transaminase was considered as liver function impairment. Bacteremia without apparent source was considered as primary bacteremia.

\section{Statistical analysis}

SPSS 11.5 for MS Windows (SPSS, Chicago, IL, USA) software was used for the statistical analysis. Kolmogorov-Smimov test was used to test if the continuous data distributed normally. One-way ANOVA test was used for the continuous data not distributing normally and unpaired Student's t test for the continuous data distributing normally. Pearson's chisquared or Fisher's exact 2-tailed test was used to examine nominal data. Univariate analyses were used to identify the risk factors associated with delayed diagnosis of scabies. The independent predictors of delayed diagnosis were identified by stepwise logistic regression of multivariate analysis. A value of $\mathrm{P}<0.05$ was considered as statistically significant.

\section{Results}

A total of 706 episodes were identified retrospectively in 399 hospitalized patients from long-term care facilities. Their demographic data and clinical characteristics were summa- rized in Table 1 . The mean age was 80 years (range, 33 to 98 years) and the overall duration of hospitalization was 14 days (range, 1 to 388 days). Mean duration from admission to diagnosis of scabies was 1 day (range, 0 to 12 days). Of 706 episodes, the patients were bedridden in $86 \%$ episodes, and had hypertension in $80 \%$ episodes. Forty-one percent of total episodes had chronic respiratory failure, $42 \%$ had diabetes mellitus, and $15 \%$ had ever had infected scabies. The patients were admitted due to bacteremia in the 225 episodes. Laboratory data within the first week of hospitalization in the 706 episodes was listed in Table 1.

Of 706 episodes, 44 episodes were considered as delayed diagnosis of scabies. Risk factors of delayed diagnosis of scabies in univariate analyses were listed in Table 2. The patients with delayed diagnosis of scabies had longer duration of hospitalization than the others (30 vs. 13 days, $P$ $<0.001)$. The ratio of the patients receiving steroid therapy chronically before admission was higher in the group of delayed diagnosis than in the other group (73\% vs. $10 \%, \mathrm{P}<$ $0.001)$. Other variables were not associated statistically with delayed diagnosis of scabies. The result of logistic regression analysis was listed in Table 3. Steroid therapy was the most important risk factor of delayed diagnosis of scabies (odds ratio: 23.493 and 95\% confidence interval: 11.354 - 48.612).

Bacteremia was noted during hospitalization in the 225 episodes. Of these, primary bacteremia was noted in the 152 episodes. The most common pathogen for primary bacte-

Table 4. Distribution of Pathogens of Primary Bacteremia in Hospitalized Patients With Scabies From Long-Term Care Facilities

\begin{tabular}{ll}
\hline Pathogens & No. of episodes \\
\hline Coagulase-negative Staphylococci & 110 \\
Staphylococcus aureus & 18 \\
Unidentified gram-positive bacilli & 16 \\
Streptococci & 3 \\
Bacillus spp. & 2 \\
Enterococci & 2 \\
Acinetobacter spp. & 1 \\
\hline
\end{tabular}


remia was coagulase-negative Staphylococcus $(72 \%)$, followed by Staphylococcus aureus (12\%), and un-identified gram-positive bacilli (11\%). The distribution of pathogens of primary bacteremia was listed in Table 4 .

\section{Discussion}

In a review of 20 hospital outbreaks of scabies, 16 of 19 index cases were considered to have crusted scabies, 16 of 19 index cases were considered to have crusted scabies or a variant [7]. Another review analyzed 19 outbreaks; all but one of the index patients had crusted scabies [10]. Patients with crusted scabies serve as a reservoir for the mite and their atypical presentation is the major cause for delayed diagnosis of scabies in these outbreaks. Several factors had been found for atypical clinical features of scabies, including HIV infection, human-T cell leukemia/lymphoma virus type 1 infection, organ transplant, elderly or debilitated individuals as well as long-term immunosuppressive medications [10]. Of these factors, our study proved chronic usage of steroid was the most important factor for delayed diagnosis of scabies in hospitalized patients from long-term care facilities. To date, there is no general policy for early and systemic detection of scabies for newcomers to a healthcare setting. However, according to the result of our study, scabies should be considered as a differential diagnosis for any atypical skin lesion on patients with chronic usage of steroid from long-term care facilities in order to avoid delayed diagnosis.

Scabies mites reside in the lower stratum corneum of the epidermis near the stratum corneum/stratum lucidum interface [11]. The intercellular fluid from lower skin zones seeps into the burrows and provides a medium for soluble antigens from the mite's body and feces to diffuse into the dermis and stimulate an inflammatory and immune response. Clinical symptoms of scabies result from a delayed host immune response to these soluble antigens [12]. Besides alleviating itching sensation, steroid could alleviate local inflammation which progresses their lesions to be camouflaged and exacerbated [13-15]. Instead of classical manifestation of scabies, this kind of patients presents as scaly, crusted papules, urticarial papules, or persistent nodules lesions [16, 17]. Orkin had ever described seven manifestations of scabies, one of which called scabies incognito as a result of modified appearance of the lesions due to use of steroids [18]. Due to variable presentations of scabies incognito, they can be easily ignored only under naked eye even by the experienced dermatologist.

Due to imprecise diagnosis of atypical skin lesions of scabies only under naked eye, skin lesions of patients with chronic usage of steroid from long-term care facilities should be microscopically confirmed. Traditionally, an oil preparation of a skin scarping or material retrieved from underneath the nails enables visualization of mites, or eggs. However, correct performance of scarping techniques requires some skill and learning. Epiluminescence microscopy is an in vivo technique with high sensitivity that allows rapid diagnosis without patient inconvenience [19]. In addition, a tape stripping method seems easier and useful to detect mites in bedridden elderly patients [20].

In previous studies, scabies is frequently associated with superinfection caused by Streptoccus pyogenes or Staphylococcus aureus, which may be associated with increased morbidity and occasionally fatal outcome [21-23]. In some reports, $S$. aureus is the most prevalent aerobic bacterium, recovered from local scabies lesions. Staphylococcal superinfection may complicate crusted scabies increasing morbidity and even mortality [10]. The same phenomenon was noted in our study, in which high ratio of patients with scabies had primary bacteremia and almost all pathogens belonged to normal skin flora. Delayed diagnosis may give more change for bacterial superinfection in patients with scabies. This may explain why longer hospitalization happened in patients with delayed diagnosis of scabies.

In conclusion, scabies is especially common among elderly patients living in long-term care facilities. Avoiding delayed diagnosis is most important to prevent scabies from spreading in the hospitals. According the result of our study, clinical physicians should pay more attention to any skin lesion in the patients receiving steroid chronically from longterm care facilities for scabies. Their skin lesions should be microscopically confirmed immediately after admission to avoid delayed diagnosis of scabies.

\section{References}

1. Sterling GB, Janniger CK, Kihiczak G, Schwartz RA, Fox MD. Scabies. Am Fam Physician 1992;46(4):12371241.

2. Chosidow O. Clinical practices. Scabies. N Engl J Med 2006;354(16):1718-1727.

3 . [Problems in nursing homes for the aged. Scabies returns--massively!]. Krankenpfl J 2002;40(1-2):38-39.

4. Buehlmann M, Beltraminelli H, Strub C, Bircher A, Jordan X, Battegay M, Itin P, et al. Scabies outbreak in an intensive care unit with 1,659 exposed individuals--key factors for controlling the outbreak. Infect Control Hosp Epidemiol 2009;30(4):354-360.

5. Obasanjo OO, Wu P, Conlon M, Karanfil LV, Pryor P, Moler G, Anhalt G, et al. An outbreak of scabies in a teaching hospital: lessons learned. Infect Control Hosp Epidemiol 2001;22(1):13-18.

6. Makigami K, Ohtaki N, Ishii N, Yasumura S. Risk factors of scabies in psychiatric and long-term care hospitals: a nationwide mail-in survey in Japan. J Dermatol 2009;36(9):491-498. 
7. Lettau LA. Nosocomial transmission and infection control aspects of parasitic and ectoparasitic diseases. Part III. Ectoparasites/summary and conclusions. Infect Control Hosp Epidemiol 1991;12(3):179-185.

8. Smith DR, Sheu HM, Hsieh FS, Lee YL, Chang SJ, Guo YL. Prevalence of skin disease among nursing home patients in southern Taiwan. Int J Dermatol 2002;41(11):754-759.

9. Charles PE, Doise JM, Quenot JP, Aube H, Dalle F, Chavanet P, Milesi N, et al. Candidemia in critically ill patients: difference of outcome between medical and surgical patients. Intensive Care Med 2003;29(12):21622169.

10. Vorou R, Remoudaki HD, Maltezou HC. Nosocomial scabies. J Hosp Infect 2007;65(1):9-14.

11. Arlian LG, Runyan RA, Achar S, Estes SA. Survival and infectivity of Sarcoptes scabiei var. canis and var. hominis. J Am Acad Dermatol 1984;11(2 Pt 1):210-215.

12. Holness DL, DeKoven JG, Nethercott JR. Scabies in chronic health care institutions. Arch Dermatol 1992;128(9):1257-1260.

13. Hengge UR, Currie BJ, Jager G, Lupi O, Schwartz RA. Scabies: a ubiquitous neglected skin disease. Lancet Infect Dis 2006;6(12):769-779.

14. Cabrera R, Agar A, Dahl MV. The immunology of scabies. Semin Dermatol 1993;12(1):15-21.

15. Roberts LJ, Huffam SE, Walton SF, Currie BJ. Crusted scabies: clinical and immunological findings in seventy-eight patients and a review of the literature. J Infect 2005;50(5):375-381.
16. Levine N. Scaly, crusted papules. These pruritic lesions can become epidemic in nursing home residents. Geriatrics 1997;52(10):90.

17. Moberg SA, Lowhagen GB, Hersle KS. An epidemic of scabies with unusual features and treatment resistance in a nursing home. J Am Acad Dermatol 1984;11(2 Pt 1):242-244.

18. Orkin M. Today's scabies. JAMA 1975;233(8):882-885.

19. Argenziano G, Fabbrocini G, Delfino M. Epiluminescence microscopy. A new approach to in vivo detection of Sarcoptes scabiei. Arch Dermatol 1997;133(6):751753.

20. Katsumata K. Simple method of detecting sarcoptes scabiei var hominis mites among bedridden elderly patients suffering from severe scabies infestation using an adhesive-tape. Intern Med 2006;45(14):857-859.

21. Heukelbach J, Wilcke T, Winter B, Feldmeier H. Epidemiology and morbidity of scabies and pediculosis capitis in resource-poor communities in Brazil. Br J Dermatol 2005;153(1):150-156.

22. Lawrence G, Leafasia J, Sheridan J, Hills S, Wate J, Wate C, Montgomery J, et al. Control of scabies, skin sores and haematuria in children in the Solomon Islands: another role for ivermectin. Bull World Health Organ 2005;83(1):34-42.

23. Davis JS, Currie BJ, Fisher DA, Huffam SE, Anstey NM, Price RN, Krause VL, et al. Prevention of opportunistic infections in immunosuppressed patients in the tropical top end of the Northern Territory. Commun Dis Intell 2003;27(4):526-532. 